\begin{tabular}{l|l|l|l}
$\begin{array}{l}\text { Case Reports in } \\
\text { Deillati. }\end{array}$ & $\begin{array}{l}\text { Case Rep Dermatol 2011;3:74-79 } \\
\text { DOI: } 10.1159 / 000326944\end{array}$ & $\begin{array}{l}\text { Published online: } \\
\text { March 25, 2011 }\end{array}$ & $\begin{array}{l}\text { O 2011 S. Karger AG, Basel } \\
\text { ISSN 1662-6567 } \\
\text { www.karger.com/cde }\end{array}$ \\
\hline
\end{tabular}

\title{
Three-Dimensional Image Fusion of SPECT and CT Scans for Locating Sentinel Lymph Nodes in Malignant Melanomas
}

\author{
Michiko Akiyama ${ }^{a}$ Takashi Ueno ${ }^{a}$ Sachiko Noro ${ }^{a}$ \\ Shinichiro Kumita ${ }^{b}$ Seiji Kawana ${ }^{a}$ \\ Departments of a Dermatology and ${ }^{\mathrm{b}}$ Radiology, Nippon Medical School, \\ Tokyo, Japan
}

\section{Key Words}

Image fusion, three-dimensional · Sentinel lymph node · Malignant melanoma

\begin{abstract}
Image fusion software can derive a fusion image from single photon emission computed tomography and computed tomography scans. We applied a three-dimensional fusion image to detect sentinel lymph nodes (SLNs) in 3 patients with malignant melanomas of the lumbar, vulvar and head region, respectively. During each operation, we detected SLNs at the expected site, as indicated by the fusion images. The three-dimensional image fusion could thus be confirmed as a simple and helpful method for precisely localizing SLNs in these patients.
\end{abstract}

\section{Introduction}

Image fusion software can derive a fusion image from single photon emission computed tomography (SPECT) and computed tomography (CT) scans [1-5]. The fusion method has the advantage of being cost-effective without the need of special equipment, compared to the SPECT/CT system, which is a hybrid imaging method consisting of a SPECT camera and a CT scanner combined in a single device.

Since 2003, fusion images have been used to detect sentinel lymph nodes (SLNs) in patients with skin cancer including melanoma, head and neck cancer [4], vulvar [5] and prostate [2] cancer, and especially cancer in areas with multiple and varied lymphatic drainage patterns or SLNs adjacent to the primary lesion [2]. Here, we report the use of three-dimensional (3D) fusion images of SLNs in 3 patients with malignant melanomas in the lumbar, vulvar and head region, respectively. 


\begin{tabular}{|c|c|c|c|}
\hline Case Reports in & $\begin{array}{l}\text { Case Rep Dermatol 2011;3:74-79 } \\
\text { DOI: } 10.1159 / 000326944\end{array}$ & $\begin{array}{l}\text { Published online: } \\
\text { March 25, } 2011\end{array}$ & $\begin{array}{l}\text { ( } 2011 \text { S. Karger AG, Basel } \\
\text { ISSN } 1662-6567 \\
\text { www.karger.com/cde }\end{array}$ \\
\hline
\end{tabular}

\title{
Case Reports
}

\author{
Case 1
}

A 65-year-old woman was referred to our hospital for the examination of a black, partially erosive nodule that had existed for more than 5 years on her median lower back. We diagnosed the lesion as a malignant melanoma. Multi-detector computed tomography (MDCT; Light Speed 32; GE Healthcare Japan, Tokyo, Japan) and positron emission tomography indicated that there were no metastases of the lymph nodes or other organs. One day before the operation, the patient underwent a pre-operative lymphoscintigraphy to identify the site of the SLN. A dose of $0.2 \mathrm{ml} 14.8 \mathrm{MBq}$ Tc-99m phytate was injected intradermally at 4 points around the lesion. A dual-head gamma camera (BrightView; Hitachi Medical Corporation/Philips, Tokyo, Japan) produced static images at $15 \mathrm{~min}$ and at $2 \mathrm{~h}$ after injection. The right inguinal basin was shown to contain a hot node. Using an image fusion software (Syntegra; Pinnacle; ADAC, Milpitas, Calif., USA), the fusion images were produced based on SPECT and MDCT scans after the delayed planar images. To adjust the alignment of both images correctly, we overlapped the navel site on the SPECT and MDCT scans. In order to accurately determine the location of the regional hot lymph node, we composed the fusion image in 3 views - transaxial, sagittal and coronal slices - using an ordered-subset expectation maximization algorithm (Astonish; Philips; fig. 1a). We then manipulated the volume rendering function to reconstruct the 3D images (fig. 1b). The hot node was clearly evident in the right inguinal basin. It was located anterointernally to the femoral artery and vein at the height of the pubic symphysis. Patent blue dye was injected at the tumor site just before the operation. The blue dye and the hand-held gamma probe techniques were used in combination during the intraoperative SLN mapping. We detected the node at the expected site, as indicated by the 3D fusion image.

\section{Case 2}

A 41-year-old woman presented with an 8-month history of a black nodule on the left labium majus. It was a pedunculated lesion with partial erosions and depigmented maculae. An excisional biopsy of the tumor revealed a malignant melanoma. The 3D images of the SLN (fig. 2) were obtained in the same manner as in Case 1. Hot nodes were present bilaterally in the inguinal basin. The signal intensity was hotter in the left than in the right inguinal basin. During the operation, 2 lymph nodes in the left and 1 in the right inguinal basin were confirmed as SLNs. Each node was harvested from the expected site, as indicated by the $3 \mathrm{D}$ fusion images.

\section{Case 3}

A 28-year-old man presented with a 10-year history of a black macule on the right parietal region of his head. Three months before the first visit to our hospital, a nodule in the macule was noticed. Biopsy findings of the lesion revealed a malignant melanoma. We constructed 3D images of the SLN (fig. 3 ) in the same manner as described in Case 1. To adjust the alignment, 3 markers (capsules with about 7.4 $\mathrm{MBq}$ Tc-99m pertechnetate) were fixed on the glabella, the mentum and the left porus acusticus. Two hot nodes were present in the parotid region. During the operation, 2 SLNs were detected. Each node was located at the expected site in the parotid gland.

\section{Discussion}

The SPECT/CT system is reportedly useful for SLN biopsy [6-10]. SPECT detects gamma rays and produces the data of radioactive distribution in a 3D format, while CT illustrates the anatomical details of a body. Therefore, the SPECT/CT technique can show the exact location of SLNs. Wagner et al. [10] reported significant differences $(\mathrm{p}=0.0015)$ between the blue dye method only and the SPECT/CT method in detecting the number of SLNs in the neck area. van der Ploeg et al. [7] stated that the detailed anatomical 


\begin{tabular}{|c|c|c|c|}
\hline 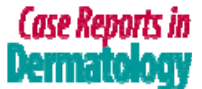 & $\begin{array}{l}\text { Case Rep Dermatol 2011;3:74-79 } \\
\text { DOI: } \underline{10.1159 / 000326944}\end{array}$ & \begin{tabular}{|l} 
Published online: \\
March 25, 2011
\end{tabular} & $\begin{array}{l}\text { O } 2011 \text { S. Karger AG, Basel } \\
\text { ISSN 1662-6567 } \\
\text { www.karger.com/cde }\end{array}$ \\
\hline
\end{tabular}

information obtained from SPECT/CT was particularly helpful in patients with a melanoma in the head and neck. They also showed that in 30 of the $85(35 \%)$ patients studied, there were clear advantages of using the SPECT/CT system over conventional planar lymphoscintigraphy, which resulted in the surgeons' altering their incisions [7].

In 2003, Kretschmer et al. [1] introduced the fusion of SPECT and pelvic CT scans of patients with malignant melanoma of the leg or the lower part of the body. They stated that the fusion image was an excellent tool to determine the exact location of pelvic SLNs. In 2005, Kizu et al. [2] used SPECT and CT fusion images to detect pelvic SLNs in prostate cancer patients. They also concluded that fusion images are useful in precisely locating SLNs. While Kizu et al. [2] recognized the usefulness of the SPECT/CT system for SLN mapping, they also discussed drawbacks of the system: it is expensive and requires extra space for installation. They reported that such drawbacks are not specific to the fusion of SPECT and CT images.

In our patients, the 3D fusion technique provided such concrete images of SLN locations in the inguinal and head/neck basin that the surgeons could precisely perform an SLN biopsy. Another benefit of the 3D fusion images was that the patients, their families and the medical staff could understand the schematic information of the SLN sites more easily. Taking into account the reproducibility of patient positioning, the fusion technique seems to be well suited especially for patients with melanomas arising from the trunk or head, since marking spots adjust for the positional error. Thus, we conclude that 3D image fusion was confirmed as a simple and helpful method for precisely localizing SLNs in these patients. 


\begin{tabular}{|c|c|c|c|}
\hline $\begin{array}{l}\text { Cose Reports in } \\
\text { teilatid. }\end{array}$ & \begin{tabular}{|l} 
Case Rep Dermatol 2011;3:74-79 \\
DOI: $10.1159 / 000326944$
\end{tabular} & \begin{tabular}{|l} 
Published online: \\
March 25, 2011
\end{tabular} & $\begin{array}{l}\text { ( } 2011 \text { S. Karger AG, Basel } \\
\text { ISSN 1662-6567 } \\
\text { www.karger.com/cde }\end{array}$ \\
\hline
\end{tabular}
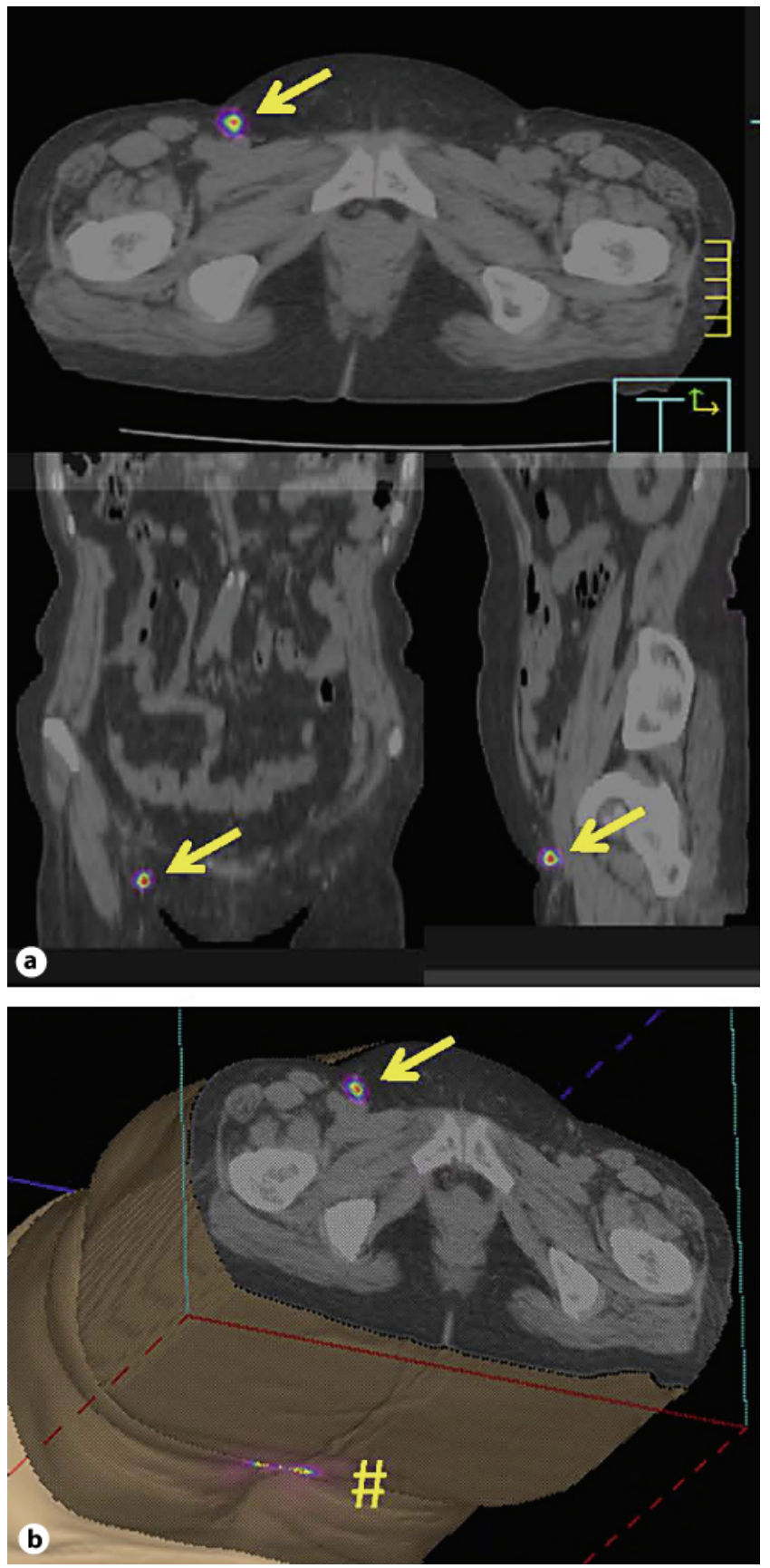

Fig. 1. 3D fusion images of the SLN in Case 1. a Transaxial, sagittal, and coronal slices of the fusion image of the SLN (arrows). b Three-dimensional image of the SLN (arrow) and the tumor site (\#). 


\begin{tabular}{l|l|l|l}
$\begin{array}{l}\text { Cose Reports in } \\
\text { Deillate.0.1) }\end{array}$ & $\begin{array}{l}\text { Case Rep Dermatol 2011;3:74-79 } \\
\text { DOI: 10.1159/000326944 }\end{array}$ & $\begin{array}{l}\text { Published online: } \\
\text { March 25, 2011 }\end{array}$ & $\begin{array}{l}\text { O 2011 S. Karger AG, Basel } \\
\text { ISSN 1662-6567 } \\
\text { www.karger.com/cde }\end{array}$ \\
\hline
\end{tabular}
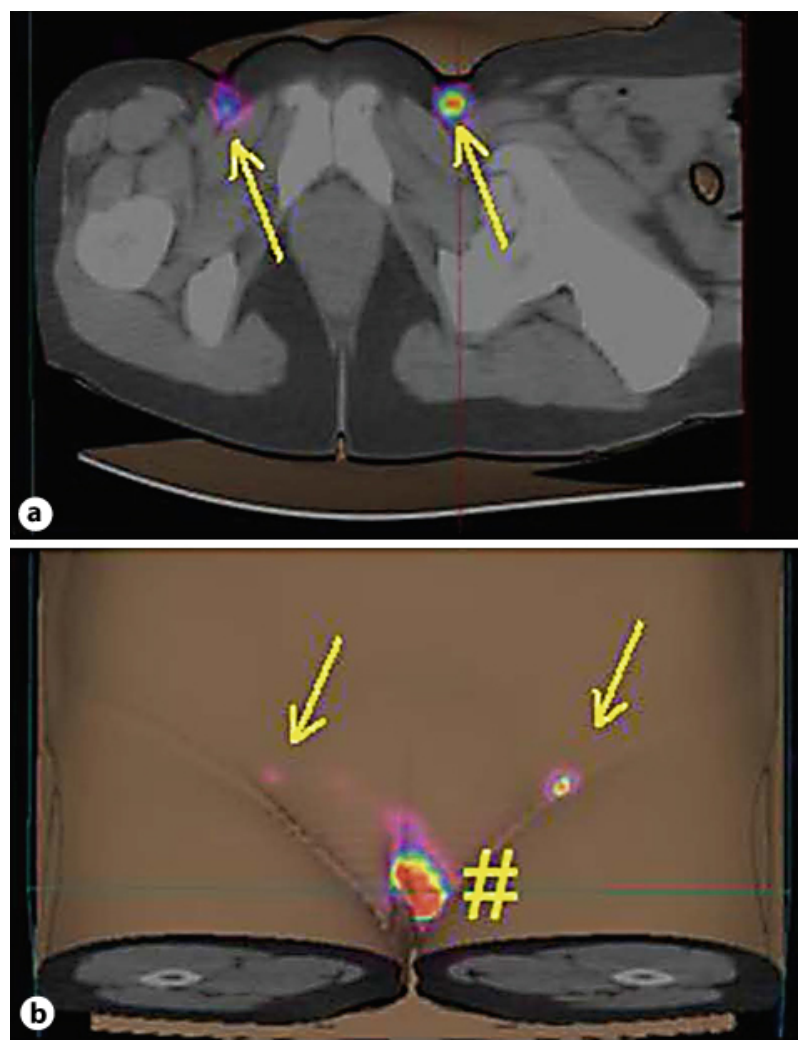

Fig. 2. 3D fusion images of the SLNs in Case 2. The SLNs are denoted with arrows. Note the hotter signal in the left inguinal basin compared with the right inguinal basin. The original tumor site is depicted as the hottest (\#).
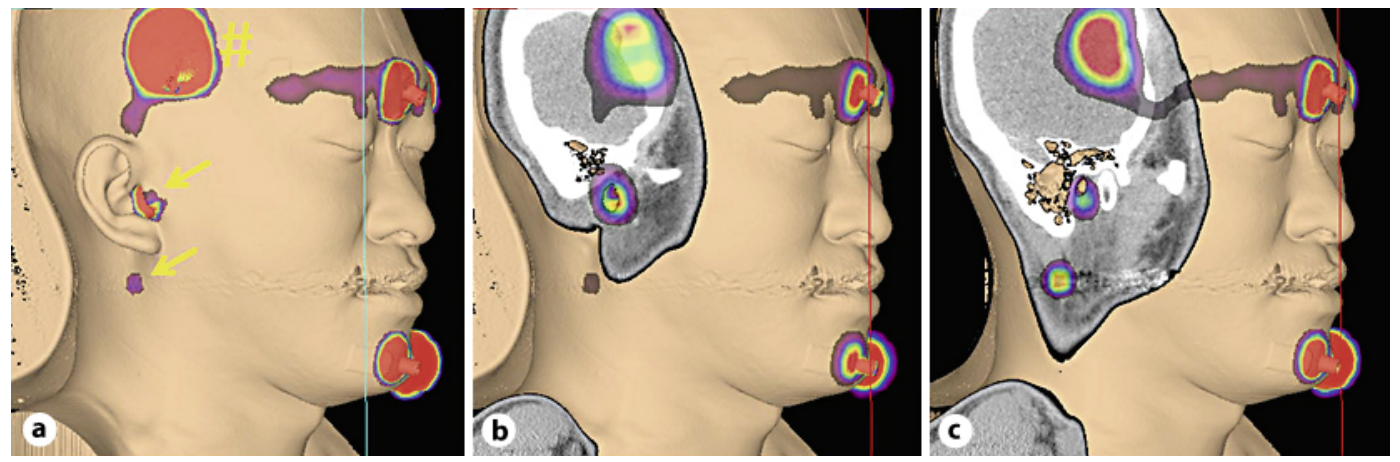

Fig. 3. 3D fusion images of the SLNs in Case 3. a Image demonstrating the SLNs (arrows) and the original tumor site (\#). b, c Images showing the sagittal slice of the fusion image of the SLN. Levels of slices were superficial (b) and deep (c) parotid nodes. Capsules with Tc-99m pertechnetate fixed on the glabella and mentum were markers to adjust the alignment. 


\section{References}

-1 Kretschmer L, Altenvoerde G, Meller J, Zutt M, Funke M, Neumann C, Becker W: Dynamic lymphoscintigraphy and image fusion of SPECT and pelvic CT-scans allow mapping of aberrant pelvic sentinel lymph nodes in malignant melanoma. Eur J Cancer 2003;39:175-183.

-2 Kizu H, Takayama T, Fukuda M, Egawa M, Tsushima H, Yamada M, Ichiyanagi K, Yokoyama K, Onoguchi M, Tonami N: Fusion of SPECT and multidetector CT images for accurate localization of pelvic sentinel lymph nodes in prostate cancer patients. J Nucl Med Technol 2005;33:78-82.

-3 Tsujino Y, Kusatake K, Kaneko S, Yamamoto Y, Furumura M, Morita E: Fusion of single-photon emission computed tomography and computed tomography images of sentinel lymph nodes in extramammary Paget's disease of the scrotum. J Dermatol 2007;34:712-715.

-4 Terada A, Hesegawa Y, Goto M, Sato E, Hyodo I, Ogawa T, Nakashima T, Yatabe Y: Sentinel lymph node radiolocalization in clinically negative neck oral cancer. Head Neck 2006;28:114-120.

5 Beneder C, Fuechsel FG, Krause T, Kuhn A, Mueller MD: The role of 3D fusion imaging in sentinel lymphadenectomy for vulvar cancer. Gynecol Oncol 2008;109:76-80.

-6 Even-Sapir E, Lerman H, Lievshitz G, Khafif A, Fliss DM, Schwartz A, Gur E, Skornick Y, Schneebaum S: Lymphoscintigraphy for sentinel node mapping using a hybrid SPECT/CT system. J Nucl Med 2003;44:14131420 .

7 van der Ploeg IM, Valdés Olmos RA, Kroon BB, Wouters MW, van den Brekel MW, Vogel WV, Hoefnagel CA, Nieweg OE: The yield of SPECT/CT for anatomical lymphatic mapping in patients with melanoma. Ann Surg Oncol 2009;16:1537-1542.

8 van der Ploeg IM, Valdés Olmos RA, Nieweg OE, Rutgers EJ, Kroon BB, Hoefnagel CA: The additional value of SPECT/CT in lymphatic mapping in breast cancer and melanoma. J Nucl Med 2007;48:1756-1760.

-9 van der Ploeg IM, Valdés Olmos RA, Kroon BB, Nieweg OE: The Hybrid SPECT/CT as an additional lymphatic mapping tool in patient with breast cancer. World J Surg 2008;32:1930-1934.

10 Wagner A, Schicho K, Glaser C, Zettinig G, Yerit K, Lang S, Klug C, Leitha T: SPECT-CT for topographic mapping of sentinel lymph nodes prior to gamma probe-guided biopsy in head and neck squamous cell carcinoma. J Craniomaxillofac Surg 2004;32:343-349. 